\title{
Extensive reading in an EFL classroom: Impact and learners' perceptions
}

\author{
Mohammed Ateek*(i) \\ ${ }^{a}$ Birkbeck, University of London, Department of Applied Linguistics and Communication, London and WC1B 5DT, UK
}

\begin{tabular}{l|l|l} 
Received 23 April 2020 & Received in revised form 10 August 2020 & Accepted 23 August 2020
\end{tabular}

APA Citation: Ateek, M. (2021). Extensive reading in an EFL classroom. Impact and learner's perceptions. Eurasian Journal of Applied Linguistics. 7(1), 109-131.

Doi: 10.32601/ejal.911195

\begin{abstract}
A number of studies have suggested that extensive reading can lead to gains in different language skills. Few studies on extensive reading have been conducted outside the East Asia classroom setting. This study investigated the impact of an extensive reading programme conducted over 12 weeks with 90minutes group sessions 3 times a week involving 10 Jordanian Arabic first language English foreign language learners with low-intermediate proficiency. The participants were situated in a print-rich environment, and given access to a library of graded readers, and did various extensive reading activities in and out of class. The participants were assessed for reading fluency and vocabulary knowledge before during and after the programme. In addition, the participants' perceptions of extensive reading were explored. A mixed-methods action research design was employed over an extensive reading programme. Data were collected from multiple sources (e.g., tests, interviews and diaries), and the results were both statistically and thematically analysed. The findings of the study indicate that the impact of the extensive reading approach was positive on the learners' reading fluency and vocabulary knowledge. The results also revealed a positive correlation between the amount of reading and reading fluency and vocabulary knowledge. The learners' perceptions of the extensive reading approach and its implications are also discussed.
\end{abstract}

(C) 2021 EJAL \& the Authors. Published by Eurasian Journal of Applied Linguistics (EJAL). This is an open-access article distributed under the terms and conditions of the Creative Commons Attribution license (CC BY-NC-ND) (http://creativecommons.org/licenses/by-nc-nd/4.0/).

Keywords: Extensive reading; reading fluency; vocabulary knowledge; learners' perceptions; action research

\section{Introduction}

Sufficient exposure is crucial for second language acquisition (Grabe \& Stoller, 2011). Al-Homoud and Schmitt (2009) note that reading provides input and is essential for improving second language proficiency, especially in environments where the reading input is poor. Extensive reading (ER), which entails reading large quantities of material for enjoyment, has been shown in different studies to be an effective approach in developing reading abilities and fluency and leads to various gains in foreign language (FL)/ second language (L2) skills (Al-Homoud \& Schmitt

\footnotetext{
* Corresponding author.

E-mail address: $\underline{\text { m.ateek@bbk.ac.uk }}$

http://dx.doi.org/10.32601/ejal.911195
} 
2009; Beglar \& Hunt 2014; Beglar, Hunt \& Kite, 2012; Bell 2001; Huffman 2014). A key benefit that foreign language learners derive from ER is exposure to sufficient amounts of easy and comprehensible reading input that makes learning enjoyable; this exposure leads to various gains in language skills.

Although research has shown positive effects of ER on learners' reading fluency and vocabulary knowledge, few studies have investigated this in the Arab English as a foreign language (EFL) context and in Jordan specifically (Al-Homoud \& Schmitt 2009; Al-Mansour \& Al-Shorman 2014). This setting is of interest because pleasure reading in first language (L1) is uncommon. Different studies indicate that Jordanian and Arab students' reading abilities are statistically significantly below the average (Alhabahba et al., 2016). Anderson (1999) states that EFL college students (international standards) should read at a speed of 280 words per minute. All the participants in this study were either college students or recent graduates, yet their reading speed was much lower than the average (i.e., 280 words per minute). Different reasons for the reading skill weakness have been provided, such as: the absence of reading culture and socio-economic factors (Rajab \& Al-Sadi, 2015). In fact, the issues of a lack of reading culture and poor attitudes towards reading, in the Arab world, are claimed to be common issues (Almahrooqi \& Denman, 2016). These reasons, in addition to the ineffective teaching methods and lack of reading materials, were also behind the perceived reading skill weakness. To approach this problem, weak reading skill, an action research study was conducted. More particularly, and in connection with this study, action research, using extensive reading as a proposed solution, was applied for three months to create some useful changes to the problematic situation in the Jordanian EFL classroom.

Consequently, the primary purpose of this study was to investigate the impact of ER on Jordanian EFL low-intermediate learners' reading fluency and vocabulary knowledge and their perceptions of this impact.

\section{Literature Review}

\subsection{Extensive reading}

ER is defined as reading large amounts of text and easily comprehensible materials for pleasure, enjoyment and global meaning (Bamford \& Day, 2004). This is often contrasted with intensive reading (IR) which "refers to the careful reading (or translation) of shorter, more difficult FL texts with the goal of complete and detailed understanding" (Bamford \& Day, 1997, p. 1).

Jacobs and Farrell (2012) elaborate that learners who read on a regular basis and in quantity come to enjoy the process of reading. The golden principle on which ER is based is that learners learn to read by reading (Krashen, 2011; Smith, 1994). Therefore, students should learn and read at their own level and pace in their own time. They choose to read what interests them based on their linguistic competence (Davis, 1995). What bears a great importance in the ER literature is the level of the 
reading materials offered to language learners. Day and Bamford (1998) have proposed that the input must be at the learners' current level or slightly below (i - 1).

The last three decades have witnessed a boom in studies conducted on the effectiveness of ER on language skills. As a result, ER has been found to increase learners' vocabulary knowledge and reading fluency, enhance their general language competence, develop both receptive and productive skills, develop reading strategies, increase reading motivation and foster positive attitudes towards reading in the target language (Bell, 2001; Day et al., 2011; Fernandez de Morgado, 2009; Huffman, 2014). More specifically, ER contributes to "automatising the lower-level skills of word recognition and parsing processes” (McLean \& Rouault, 2017, p. 94).

A meta-analysis of 34 studies on ER with an overall sample of almost 4,000 participants found a large effect $(d=0.71)$ in comparing pre- and post- performance in ER improvements in reading proficiency against controls (Nakanishi, 2015). In spite of the growing evidence for the benefits of ER in FL teaching contexts, there has been limited uptake of this practice in education systems. Brown (2009) and Day (2013) suggest that a number of factors may contribute to the unpopularity of ER: the ER library cost; the demands of setting up an ER programme; the difficulty of scheduling ER time in the already-crowded curriculum; teachers' reliance on traditional roles and methods and the belief that reading should come after students are able to speak and understand the FL/L2. The present study details the design and implementation of an ER programme that addresses some of these issues. The term 'programme' is used here following Davis' (1995, p. 329) definition that an ER programme is "a supplementary class library scheme, ...in which pupils are given the time, encouragement, and materials to read pleasurably, at their own level, as many books as they can". This definition informed the current study through providing the participants with various materials at their own level to read pleasurably.

\subsection{Reading fluency through ER}

Reading speed has been identified as a major contributing factor to improving one's reading comprehension and is related to reading fluency or flow. Slow reading speed, on the other hand, has a negative effect on one's general comprehension and may prevent information from reaching readers' long-term memory, which, in turn, may prevent information processing (Koda, 2005). Different component subskills form reading fluency such as decoding, word recognition, phonological representation, and syntactic and semantic parsing. Rapid recognition of words in a text activates links between the graphic form and phonological information, activate appropriate semantic and syntactic resources, recognise morphological affixation and access their mental lexicon (Perfetti, 2007). LaBerge and Samuels (1974) argue that these subskills are finite and the capacity of attention will be surpassed if each component requires attention. Therefore, effective word processing and automatisation of the subskills and lower-level skills provide readers with the opportunity to invest their 
attentional and cognitive resources in the higher-level processes of comprehension, analysis and interpretation (Nathan \& Stanovich, 1991).

Studies investigating reading fluency showed the positive impact of ER in increasing reading fluency (Beglar \& Hunt, 2014; Beglar, Hunt \& Kite, 2012; McLean \& Rouault, 2017). In a pioneering study, Robb and Susser (1989) have investigated the impact of ER on reading fluency over one academic year. Japanese university students $(n=125)$ were randomly assigned to either an ER or IR group. A pre- and post-test treatment measurement of 1-minute reading method was used. Results show that the ER group made more fluency rate gains than the IR group (86.55 vs. 76.75 words per minute (wpm), with no significance difference between the two groups before the treatment. However, some details regarding the reading texts (i.e., the materials used for reading) and tests were not specified in this study. More recently, Beglar and Hunt (2014) found that use of simplified texts within the competence of their lower-intermediate Japanese EFL university students increased their reading fluency

The importance of providing language learners in ER programmes with the freedom to self-select materials (e.g., graded readers, authentic materials) has been highlighted (Grabe, 2009). In Al-Homoud and Schmitt's (2009) study, they examined the ER effect on 70 male EFL Saudi university students' reading speed who selfselected their graded readers. Using two identical texts for measuring reading fluency, the results showed that students in the ER group (a mean gain of $33.49 \mathrm{wpm}$ ) showed greater improvements in their reading speed than those in the IR group (a mean gain of $26.13 \mathrm{wpm}$ ). However, the ER programme in this study was only intensive short course, and as a consequence it is possible that rehearsal effects may have been involved in the use of the same material for the pre- and post-test. This is similar to Iwahori's (2008) study, which investigated the effect of ER on 33 Japanese high school students over a 7 -week course. The study also used a 1-minute reading measurement with two identical texts for pre- and post-tests. The measure of reading fluency was found to be significantly higher after this short ER intervention period.

Although ER effectiveness in increasing reading fluency has been linked to the quantity of comprehensible material students are exposed to, many studies vary on reporting details of the amount or level of the texts employed. While some reported the number of words/books read by students (Beglar, Hunt \& Kite, 2012; Lai, 1993; Nishino, 2007), other studies did not specify how much was read (e.g., Bell, 2001; Mason \& Krashen, 1997)

\subsection{Vocabulary knowledge through ER}

ER can be a straightforward path for language learners to build strong vocabulary knowledge and lead to increased reading comprehension (Koda, 2005). Grabe (1988) argues that "fluent readers need a massive amount of receptive vocabulary that is rapidly, accurately, and automatically accessed and lack of such a vocabulary knowledge may be the greatest single impediment of fluent reading by ESL students" 
(p. 63). The strong correlation between vocabulary knowledge and fluent reading raises the question of how learners can expand their vocabulary knowledge.

Reading a large amount of text and materials is the main characteristic of ER, which contributes to the development of learners' vocabulary through repeated encountering of individual words (Horst, 2005). Krashen (1989) proposed, as is the case with L1 vocabulary, that L2 vocabulary knowledge can be developed and expanded through ER. To this end, Yamamoto (2011) investigated the effects of ER combined with writing tasks on 67 EFL Japanese university students' receptive and productive vocabulary knowledge through a 13 -week study. While no differences were found between the ER and control group, the ER students increased their vocabulary. This result is based on general vocabulary tests however, rather than words included in the texts used in the programme. While a strong relationship has been found between ER and increased reading comprehension (Krashen \& Cho, 1994), less research has been conducted on the relationship between ER and vocabulary learning (Horst, 2005; 2009; Kweon \& Kim, 2008).

It is this gap in research on the impact of ER on vocabulary knowledge that Horst (2005) sheds light on. She argues that research tells us little about how ER increases vocabulary knowledge, as it typically focuses on more general aspects of L2 development. She points out that ER studies taking place in English contexts (UK and US) limit the generalisability of findings, since it is difficult to determine how much the effect in such studies is due to the particularities of environment in which they took place. Horst provides evidence from her Canadian study on 21 English as a second language (ESL) adult learners at a community centre in Montreal where the dominant spoken language was French. Students had access to more than 150 books (75 different titles). Horst found that the participants increased their vocabulary knowledge and obtained new knowledge of more than half of the unfamiliar words that were in the ER materials they selected.

\subsection{Gaps in previous research}

As noted from the previous research on the effectiveness of ER on reading fluency and vocabulary knowledge, the majority of the studies show positive effects of ER on these skills. However, common limitations, including methodological deficits, among the ER studies reviewed above include: (a) identical reading texts were used for the pre and post reading fluency tests; (b) little information was provided on the procedures and delivery of the ER programmes, (c) the amount of reading was not reported, (d) general vocabulary tests rather than words from the ER materials were used, (e) the majority of studies were typically conducted with university students in East Asia and Japan.

The current study was designed to address the limitations of the previous ER studies, using an under-researched setting, namely the Arabic L1 Jordanian EFL context. This, in turn, guided the following research questions:

(1) Does ER increase Jordanian EFL learners' reading fluency? 
(2) Does ER increase Jordanian EFL learners' vocabulary knowledge?

(3) How do Jordanian EFL learners perceive the impact of ER on their reading fluency and vocabulary knowledge?

\section{Method}

\subsection{Participants}

The participants in this study were 10 Jordanian EFL learners, seven females and three males at a private language centre in Amman, Jordan. Based on records from the centre, 40 participants were initially chosen based on their similar language proficiency level (i.e., Lower-intermediate). The participants were invited for interviews before the programme had started. From this pool, 10 participants agreed to take part in the ER programme. All participants were between 21-27 years of age. Their L1 was Arabic and they were learning English as a FL, but they were not enrolled in any English language course during the study. This final requirement was to ensure to minimise their exposure to the target language apart from the treatment.

Participants had an average of 12 years of English language learning experience (ranging from 10 to 16 years, SD: 2). Participation in the study was voluntary for the learners; however, earning a certificate of programme completion served to motivate them. In a pre-programme interview, all learners reported that they had never been enrolled in any ER course and they rarely read books for pleasure in the L2. To protect the participants' privacy and confidentiality, their names are coded as: S1, S2, etc. as an abbreviation for student.

\subsection{Design of study}

This classroom-based, mixed-methods action research used a stand-alone separate ER programme. Action research is an integration of theory and action with the aim of addressing different issues together with those who are involved (Coghlan \& BrydonMiller, 2014). It must be stressed that action research is contextual in the sense that it views classrooms as unique entities and the results apply to the particular setting where the investigation takes place. Therefore, similar to other action research studies on ER (Iwahori, 2008; Cirocki, 2009), this study is localised, contextualised and aimed at discovering, monitoring and leading change to practice. Replicating studies across different settings could help with the general understanding of the enquiry, since action research is a "systematic approach to enquiry... to identify problematic situations in order to bring about critically informed changes in practice" (Burns, 1999, p. 5).

The four systematic phases (stages) for carrying out an action research, proposed by Kemmis and McTaggart (1998), were followed in this study. Those are: 1) identifying a problem, 2) designing a plan and deliberate intervention, 3) observing the effects and collecting all data and 4) reflecting and evaluating the action. After identifying the problem (weak reading skill and slow reading speed), a plan was developed in 
order to improve the learning process; that is, setting up an ER programme in the Jordanian EFL classroom (i.e., deliberate intervention as a proposed solution to the problem). I put the action into practice using mixed methods tools to collect the data for later evaluation and research analysis.

Although some researchers view action research as using primarily qualitative methods, this study used triangulation to provide a comprehensive understanding for the research questions.

\subsection{Materials}

The reading materials provided for the ER programme were graded readers, which are defined as narrative texts written for a community of FL/L2 readers and are controlled for syntax, sentence length and complexity and vocabulary (Day et al., 2011). These graded readers were either re-writes or simple originals from three different series: Cambridge English Readers (Cambridge University Press), Oxford Bookworms (Oxford University Press) and Penguin Readers (Pearson).

The selection of reading materials was made by the participants before the programme started as follows: the participants were divided into 3 groups (group 1and 2, n= 3; group 3, $n=4$ ) and each group was asked to create a list of 15 titles selected from all the available books. Approximately 250 books, with 57 different titles, were chosen by the learners for reading. The available graded readers varied in their genres (e.g., thrillers, detective stories, true stories, romance, fact-files) to cater to the participants' various interests.

Most books were level 3 (lower-intermediate), in accordance with the participants' language proficiency level, ranging from 1000 to 1300 headwords. However, some intermediate-level books (level 4) were also provided for the more effective participants and for those who increased their linguistic abilities throughout the programme. After gaining a final list of graded readers, another second set of level 3 class readers was created (see Table 1). The participants were also encouraged to read the same 3 class readers taken from this list each month (i.e., 9 class readers over the 3 -month period) in addition to their own individual choices. These class readers provided common materials for classroom activities, language and vocabulary exercises, oral and written presentations, and group/peer discussions. For example, a participant in every lesson had to present a book they had read during the week, using either PowerPoint slides or narrating the story of the book with the help of cue cards. Other activities such as matching book blurbs with titles, vocabulary quizzes, watching videos related to class readers and commenting in group discussions were also used.

Table 1. List of class readers 


\begin{tabular}{|c|c|c|c|c|}
\hline Book title & Author & Genre & Publisher & $\begin{array}{l}\text { Number of } \\
\text { words }\end{array}$ \\
\hline Chemical Secret & Tim Vicary & Thriller \& Adventure & Oxford & 10150 \\
\hline Dancing with Strangers: & Clare West & World Stories- Fiction & Oxford & 11990 \\
\hline \multicolumn{5}{|l|}{ Stories from Africa } \\
\hline How I Met Myself & David Hill & Ghost Story & Cambridge & 12597 \\
\hline Martin Luther King & Alan McLean & Fact-files & Oxford & 9871 \\
\hline Rabbit-proof Fence & Doris Garimara & True Stories & Oxford & 10600 \\
\hline \multirow[t]{3}{*}{ Sense and Sensibility } & Jane Austen. & Romance & Penguin & 7924 \\
\hline & Retold by Cherry & & & \\
\hline & Gilchrist & & & \\
\hline Stories of Survival & Fiona Beddall & True Stories & Penguin & 9778 \\
\hline The Last Sherlock & Michael Dibdin & Crime \& Mystery & Oxford & 9680 \\
\hline \multicolumn{5}{|l|}{ Holmes } \\
\hline \multicolumn{5}{|l|}{ Story } \\
\hline Two Lives & Helen Naylor & Romance & Cambridge & 14404 \\
\hline
\end{tabular}

A small library was created and books were arranged according to the publisher, genre, level and whether they were class readers or graded readers. A check-in and check-out system was created at the beginning of the programme. This system created two opportunities: knowing who borrowed and returned the books, and identifying the total number of the books each participant read.

Participants were encouraged to read as much as possible in and out of class. In each 90-minute lesson, students had about 30 minutes of scaffolded silent reading. However, they had a reading minimum target of 5 graded readers a month (i.e., 15 graded readers over 3 months). To estimate the number of words read, the average number of words in the class readers was calculated from the 3 publishers. The average was 10,800 words per book. Evidence of the books read by participants came from the records of the ER library check-in check-out system, participants' book reports and also their diaries.

Each book report contained five parts: 1) the details and date of the book they read, 2) a summary of its contents, 3) new words they had learned, 4) their feelings about and reaction to a book. A final section was for teacher feedback. A modified version of the Cambridge University Press book report form (2004) was used.

\subsection{Measurement instruments}

\subsubsection{Reading fluency tests}

Two one-minute reading fluency tests were conducted at the beginning of the programme, and then two more at the end of the programme. The first two reading 
fluency tests served as pre-tests, and were conducted over the same text but on separate days given two days apart to establish a baseline. These two measures were combined to provide a mean reading fluency measure. The two reading fluency posttests employed a different text, also delivered twice two days apart.

Both of the texts were chosen from the same graded reader (Playing with Fire: stories from the Pacific Rim by Jennifer Basssett 2009) (level 3) to avoid measuring reading fluency over texts with different genres, styles and difficulty levels. Thus, being written by the same author, and in the same book, the texts were created in the same style and at the same level of difficulty and structure. To measure the readability levels of the reading passages used as pre- and post-tests, the FleschKincaid Grade Level formula was used. The results produced were Flesch-Kincaid Grade Level 6.3 for pre-test and 6.4 for post-test (i.e., almost identical reading difficulty levels). The number of words was recorded over the period of 1 minute to give a reading fluency measure in wpm.

\subsubsection{Vocabulary tests}

Three 15-minute in-class vocabulary tests were conducted; all were multiple-choice with four responses for each question. The tests were used to assess the knowledge of the 20 most frequent words found in the nine class readers (60 words in total). These words are usually included in glossaries at the end of graded readers, and they have been used in the vocabulary tests. To ensure content validity of the tests, the vocabulary tests were evaluated by an expert and some questions were modified as a result to make the multiple-choice questions appropriate, relevant and representative of the construct being examined (Haladyna, 1999). As far as the reliability of the tests is concerned, reliability analysis revealed Cronbach's alpha scores of $\alpha=.77$ (test 1), $\alpha$ $=.75$ (test 2 ) and $\alpha=.83$ (test 3 ). These scores indicate that the vocabulary tests are acceptably reliable (Gravetter \& Wallnau, 2000)

Every monthly test, pre or post, was used to check the participants' vocabulary knowledge of the three assigned class readers of that month. There were three vocabulary tests that assessed the knowledge of 20 words from the class readers: 1 ) Rabbit-proof Fence, Sense and Sensibility and Two lives; 2) Chemical Secret, Stories of Survival and The Last Sherlock Holmes Story; and 3) How I Met Myself, Martin Luther King and Dancing with Strangers: Stories from Africa.

Each of these three tests was applied twice, as pre- and post-tests. Clear and full instructions of the test and time limits were given to participants before they started to individually work on the test. The total mark for each test was 20, where every correct answer was given (1) mark, while every wrong answer was given (0) mark.

\subsubsection{Interviews}

In order to probe the participants' learning and reading experience, perceptions of the impact of ER, motivation and attitudes to reading and ER, two semi-structured, 
open-ended interviews with each participant were conducted: one at the beginning of the programme and one when the programme was over. The first explored the participants' socio-cultural demographics, feelings and thoughts about reading, reading strategies, past reading experiences, and their thoughts about ER. The second interview aimed at discovering their perceptions of their ER experience, their reading strategies, their motivation and attitudes to reading English books and their perception of the impact of ER on their proficiency levels.

The interview questions were piloted on two EFL learners whose English proficiency level was the same as the participants (lower-intermediate). As a result, some questions were amended to improve clarity and precision and to make the overall interview time shorter. Each interview lasted approximately 15 minutes. All interviews were conducted in Arabic and were audio-recorded except two for sensitivity issues at their request. In addition, I took notes with the help of short hand codes to minimise their intrusion on the conversation.

\subsubsection{Diaries}

Diaries are often employed in language learning research to capture self-reflection on the experience and help identify particular variables that enhance or hinder language learning (Schumann \& Schumann, 1997; Cirocki, 2013). Participants were asked to keep a diary as a way to record their feelings and reflect upon their learning experience during the ER programme. They were encouraged to write their diaries in English every day. When writing entries into their diaries, they described their feelings about reading in English, their thoughts about the benefits and limitations of ER, the books they were reading and what language skills they thought they were improving.

\subsection{Procedure}

Before the ER programme started, the 10 participants were given informed consent forms with participant information sheet, explaining the purpose of the study and their involvement. After agreeing on participating in the ER programme, the participants had one orientation lesson on ER, explaining what it means and how the programme would proceed. In the first week of the programme, the participants were given reading fluency and vocabulary pre-tests for the first month, interviews were conducted, diaries and book reports to fill were distributed to the participants after explaining how. Vocabulary pre-tests were administered at the beginning of Weeks 1 , 5 and 9, while the post-tests were administered at the end of Weeks 4, 8 and 12. The reading fluency post-tests were administered at the end of Week 12. Participants had 3 lessons a week, lasting for 90 minutes each, over 12 weeks. During the ER programme, scaffolded silent reading and various in and out of class activities took place (see 3.3). Besides tests, interviews, participants' diaries and book reports were used. 


\subsection{Data analysis}

Using the statistical software package SPSS (version 19.0), paired t-tests were used to determine whether there was a difference between the results of pre- and post-tests for the reading fluency and vocabulary tests. In addition, Pearson's correlation analyses were carried out between the number of books read by each participant (i.e., amount of reading), and the participants' mean scores in tests (reading speed and vocabulary knowledge).

Data analysis for the interviews and diaries was carried out using a thematic approach of the narrative analysis (Gries, 2009). A detailed and in-depth scrutiny of the data from interviews and diaries led to a data-driven coding approach to identify the main themes through inspection of frequently used words and phrases (Creswell, 2013). For example, among the words which the participants used most frequently were reading materials, past reading experiences, anxiety and fast reading. These lead to the identification of categories and clarify how the categories are related to each other (Dörnyei, 2007). After identifying different categories and labels from initial coding, similar categories or categories that served the same theme, were grouped together. As a result, 11 main categories were derived. As multiple coding rounds increase the intra-coder reliability (Revész, 2012), these main categories were divided further with some labels and subcategories under them from the initial coding.

A portion of data was independently coded by another coder to validate the 11 categories. This step was taken to obtain more credible data and to eliminate personal biases in the analysis (Creswell, 1998). Based on the coder's feedback, some changes to the categories were made by labelling some categories as subcategories to other main categories. The final grouping of categories included six categories, each with subcategories which were used to characterise the findings: 1) past reading experiences, 2) perceptions of the impact of ER on reading fluency, 3) perceptions of the impact of ER on vocabulary knowledge, 4) perceptions of the impact of ER on reading strategies, 5) perceptions of the impact of ER on productive skills and 6) motivation for and attitudes towards reading and the ER programme. For the purposes of the present investigation, analysis focussed specifically on participants' perceptions of the ER impact on reading fluency and participants' perceptions of the ER impact on vocabulary knowledge.

\section{Results}

\subsection{Quantitative results}

\subsubsection{Reading fluency tests}

To address the first research question, the results of the reading fluency pre-tests and post-tests were combined to produce average scores for analysis (see Table 2). A paired t-test showed a statistically significant increase in the participants' reading 
fluency between pre-tests and post-tests $(d f=9, t=-12.07, p<.0001)$, as the $p$ value is less than .05 (see Table 3). While all participants' reading fluency increased, there were individual differences. The biggest increase was achieved by $\mathrm{S} 4$ (+ $25.5 \mathrm{wpm})$, while the smallest one was by S5 (+13.5 wpm). The mean number of words read per participant in pre-tests totalled 153.1, compared to 171.3 in post-tests, with a mean increase in reading fluency of $18.2 \mathrm{wpm}(S D=4.76)$ between participants' reading fluency gains.

Table 2. Participants' reading fluency: difference between pre-tests and post-tests

\begin{tabular}{llll}
\hline Student ID & Mean pre-test 1+2 & Mean post-test 1+2 & $\begin{array}{l}\Delta=\text { (post-test 1+2)-(pre-test } \\
1+2)\end{array}$ \\
& & & +25 \\
\hline S1 & 155.5 & 180.5 & +16.5 \\
S2 & 169.5 & 186 & +16 \\
S3 & 135 & 151 & +25.5 \\
S4 & 125 & 150.5 & +13.5 \\
S5 & 180 & 193.5 & +14.5 \\
S6 & 145.5 & 160 & +14 \\
S7 & 148 & 162 & +18 \\
S8 & 162 & 180 & +15 \\
S9 & 164.5 & 179.5 & +24 \\
S10 & 146 & 170 & +18.2 \\
\hline Mean & 153.1 & 171.3 & $+13.5 /+25.5$ \\
\hline Min/Max & $125 / 180$ & $150.5 / 193.5$ &
\end{tabular}

Table 3. Paired T-test results of reading fluency pre- and post-tests

Paired Samples Test

Paired Differences

95\% Confidence Interval of the Difference

\begin{tabular}{|c|c|c|c|c|c|c|c|c|c|}
\hline & \multirow[b]{2}{*}{ Mean } & \multirow[b]{2}{*}{$\begin{array}{l}\text { Std. } \\
\text { Deviation }\end{array}$} & \multirow[b]{2}{*}{$\begin{array}{l}\text { Std. Error } \\
\text { Mean }\end{array}$} & & \\
\hline & & & & & Lower & Upper & $\mathrm{t}$ & $\overline{\mathrm{df}}$ & $\begin{array}{l}\text { Sig. (2- } \\
\text { tailed) }\end{array}$ \\
\hline Pair 1 & $\begin{array}{l}\text { Pre-tests - } \\
\text { Post-tests }\end{array}$ & -18.20000 & 4.76795 & 1.50776 & -21.61078 & -14.78922 & -12.071 & 9 & .000 \\
\hline
\end{tabular}


Data from the pre- and post-tests indicate that being exposed to ER and surrounded by varied, interesting and easy materials had a significant positive effect on their reading fluency (a mean increase of $18.2 \mathrm{wpm}$ ).

To check the correlation between the amount of reading and the results of the reading speed tests, the amount of reading by the participants was calculated. Reading, in terms of books, varied widely among them, between 15 and 32, with an average of 21 books read by each participant during the programme. A Pearson's Correlation analysis revealed a positive relationship between the number of books read by each participant and the participants' mean reading fluency after the ER programme $(r(9)=0.79, p<.006)$. This suggests that the more the participants read, the faster their reading became (see Figure. 1).

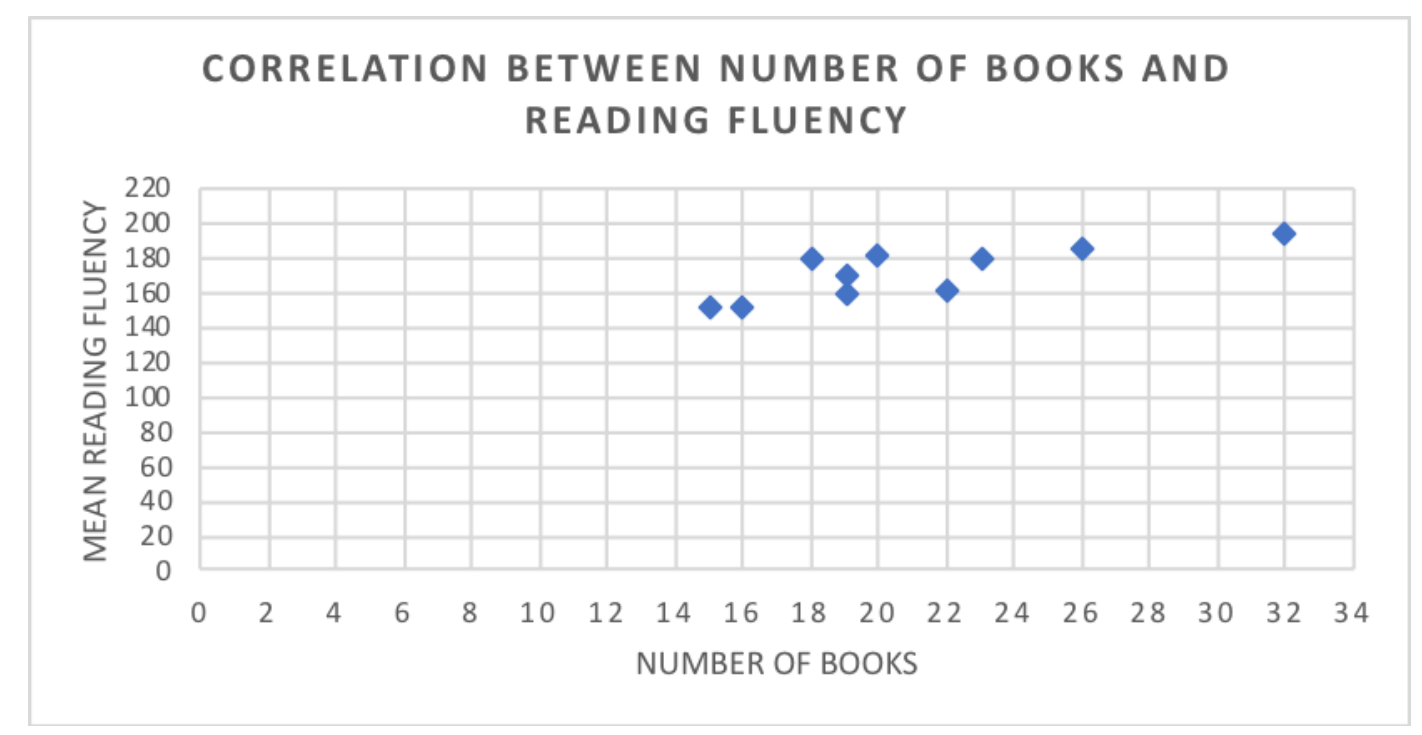

Figure 1. Correlation between number of books read and reading speed

\subsubsection{Vocabulary knowledge tests}

The results of the pre- and post- vocabulary tests were combined to produce average vocabulary scores. Table 4 provides the average scores in all tests for each individual student. 
Table 4. Average results of all vocabulary tests

\begin{tabular}{llll}
\hline & \multicolumn{2}{c}{ All Vocabulary Tests $(n=20)$} & $\Delta$ \\
Student ID & PRE & POST & +7.33 \\
\hline S1 & 2.66 & 10 & +9.66 \\
S2 & 3.66 & 13.33 & +6.33 \\
S3 & 1.66 & 8 & +5.66 \\
S4 & 2 & 7.66 & +10 \\
S5 & 5 & 15 & +7.32 \\
S6 & 2.33 & 9.66 & +7.99 \\
S7 & 3.66 & 11.66 & +7.33 \\
S8 & 4 & 11.33 & +7.99 \\
S9 & 3.33 & 11.33 & +7.33 \\
S10 & 1.66 & 9 & +7.69 \\
\hline Mean & 3 & 10.69 & 1.32 \\
\hline SD & & & \\
\hline
\end{tabular}

A paired t-test revealed a statistically significant increase in the participants' vocabulary knowledge between pre-tests and post-tests after experiencing the ER programme for 12 weeks ( $d f=9, t=-18.32, p<.000$ ) (see Table 5). The best result was achieved by S5 with an average increase of 10 newly acquired words per month, and the poorest one was achieved by $\mathrm{S} 4$ with an average increase of 5.7 words per month. The participants' mean growth of vocabulary amounted to 7.7 newly gained words per month $(S D=1.3)$.

Table 5. Paired T-test results of vocabulary pre- and post-tests

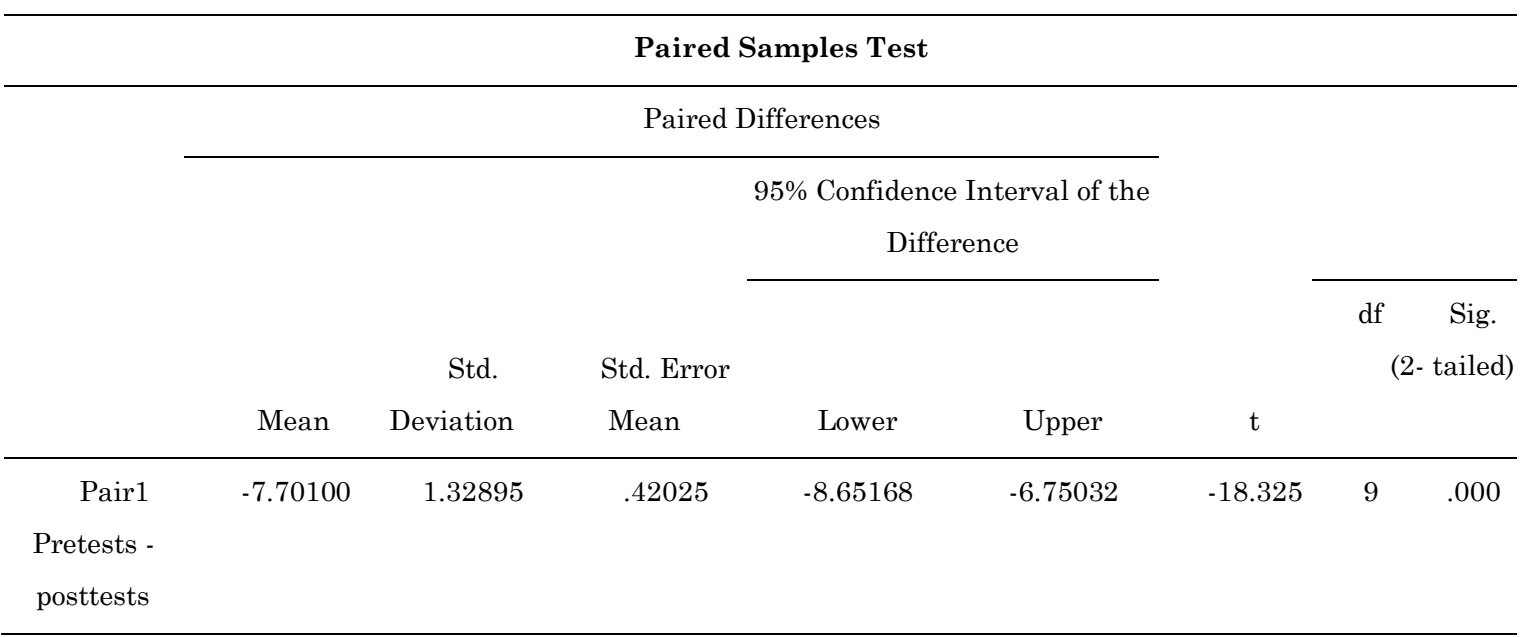


The results in Table 4 is not a measure of all new words gained either monthly or in the whole ER programme, rather it validates that the participants learned at least this number of new words from 20 they encountered in each of the readers. It does not capture other words that may have been learned from exposure to these books, nor does it investigate new vocabulary gained through the reading of the self-selected books by each participant. As such it is a very conservative estimate of their possible attainment in vocabulary growth as a consequence of their ER experience. In order to get a better approximation of the number of new words acquired by each participant during the ER programme, details from the book reports were also analysed. The number of books read (both class readers and graded readers), and the number of newly gained words recorded by each participant are shown below in Table 6 .

Table 6. The number of books read and the newly acquired words for each participant

\begin{tabular}{lll}
\hline Student ID & Number of books & Recorded number of new words \\
\hline S1 & 20 & 118 \\
S2 & 26 & 94 \\
S3 & 16 & 90 \\
S4 & 15 & 106 \\
S5 & 32 & 102 \\
S6 & 19 & 126 \\
S7 & 22 & 97 \\
S8 & 18 & 117 \\
S9 & 23 & 108 \\
S10 & 19 & $90 / 151$ \\
\hline Min/Max & $15 / 32$ & 110.9 \\
\hline Mean & 21 & \\
\hline
\end{tabular}

A Pearson Correlation revealed a strong significant positive relationship between the amount of reading and the participants' mean growth of vocabulary $(r(9)=0.96, p$ $<.0001)$.

\subsection{Qualitative results}

Participants in this study showed similarities in their reflections and comments which led the identification of emerging themes: self-explanation of the reasons behind their perceived slow reading, their perceptions of the ER impact on reading fluency and vocabulary knowledge and initial fear of ER materials. There were also differences between the participants in their different levels of motivation, reading targets, reported FL anxiety and levels of involvement in activities and tasks. Due to 
the limited space, the analysis of results will be restricted to the participants' perceptions towards the ER impact on reading fluency and vocabulary knowledge. Table 7 demonstrates the main categories and subcategories, and the number of tokens present in the interviews and diaries. Some of the most typical comments are presented as illustrations of each theme.

Table 7. Themes and subthemes and the number of tokens in the interviews and participants' diaries

\begin{tabular}{ll}
\hline Categories & subcategories \\
\hline Participants' perceptions (76) & The perceived impact of ER on reading fluency (42) \\
& The perceived impact of ER on vocabulary knowledge \\
$(34)$. \\
\hline
\end{tabular}

\subsubsection{Participants' perceptions of the ER impact on reading fluency and vocabulary knowledge}

The participants provided abundant data related to their perceptions and beliefs about ER after experiencing it for 12 weeks. First, the participants' self-reported evaluation of the ER impact on reading fluency was positive and shared among all participants with no exception. Participants also started to realise the essentiality of consistent reading to obtain fluent reading. For example, the participant who scored the highest in reading fluency commented:

The more I read the faster I become in reading. I noticed that similar words and sentences are repeated in the same book and this is very helpful to memorise the words and read faster. (S5, interview)

Another participant, S10, wrote in his diary, "I was really slow [reader] but after reading more books, my reading speed is getting much better". $\mathrm{S} 10$ attributed this sense of achievement to the "good and easy books"; something that was reported by all participants in their diaries. The graded readers, chosen by the participants based on their interests and proficiency level, also equipped them with a reading fluency practice. One of the participants commented:

I am so glad that these graded readers are easy with different genres; this gives me more options to choose the books that suit my interests and tastes for reading. This made my reading faster. (S1, diary) 
This typical response indicates the student's realisation of the importance of graded readers in her reading speed gains.

Secondly, and similar to the comments above about the impact of ER on reading fluency, participants reported positively on the ER impact on vocabulary knowledge. The majority of the participants felt a sense of achievement regarding their vocabulary knowledge because of reading. For example, one participant wrote in her diary:

I finished "Sense and Sensibility" and I learned many new words such as: greedy, anxiously, priest, handkerchief, amusing, pills, and sensible... I found it very helpful that I went through these words many times while I was reading the novel, and to make more practice, the teacher asked us to fill in the book reports after we finish reading any book. (S1, diary)

The above comment demonstrates two points: the first is that the participant realised the effectiveness of ER, and graded readers in particular, as a tool for learning new and unfamiliar words as the target words were encountered many times in different contexts and so the chances for gaining new words were high (Hill, 2008); the second point is that the participant viewed book reports as exercises, which made them more interesting, rather than as obligatory assignments, taking into account that participants had the freedom to practise new words or not. Comments from other participants were found to be similar and positive, especially in relation to the variety of genres in graded readers and how that had enhanced their vocabulary in different topics. For example, S8 commented:

I gained vocabulary in different fields since I read different books with different genres and topics, such as: insect, raft, sting, dissolve, absorb, chemical reaction, segregation and many others. (S8, interview)

Another participant (S7) commented in her diary:

Reading helped me a lot in knowing new words without making effort to memorise. It is like [an] automatic process. When I read more, I increase my words more. (S7, diary)

This comment refers to an important aspect that the participants admired about ER; that was the automaticity of learning new words as they read, without using the traditional way of memorising words, mainly out of context.

\section{Discussion}


The first research question examined the impact of ER on Jordanian EFL learners' reading fluency over a 12 -week ER course. The results of reading fluency post-tests show a statistically significant increase in the participants' reading fluency and suggest that the ER programme was an effective method for increasing the participants' reading fluency (mean $=+18.2 \mathrm{wpm}$ ). This is in line with findings from previous studies (Bell, 2001; Al-Hamoud \& Schmitt, 2009; McLean \& Rouault, 2017). Although all the participants reported reading rate gains with a mean increase of +18.2 words per minute, the reading rate gains in this study are less than those reported in Bell's (2001) study (mean $=+59.4 \mathrm{wpm}$ ), but similar to those found in Beglar, Hunt \& Kite's (2012) study (mean= +16.8wpm) and Huffman's (2014) study $($ mean $=+20.7 \mathrm{wpm})$. This could be due to the variation in the length of the ER programme. However, contextual factors may also be an important contributor to the patterns of findings reported here. These Jordanian EFL participants had relatively low reading speeds for low-intermediate learners at the outset of the study (mean= $153.1 \mathrm{wpm})$.

There is a close and strong link between reading fluency, enjoyment and reading comprehension. Nuttal (1996, p. 127) describes the vicious circle of the weak reader as follows: "Reads slowly; Doesn't enjoy reading; Doesn't read much; Doesn't understand; Reads slowly". The findings from the present study suggest that ER can help readers enter a cycle of growth, through providing large amounts of self-selected reading material at or slightly below the level of proficiency with a wide variety of genres. This echoes the findings of Beglar, Hunt \& Kite's (2012) study which concluded that large amounts of pleasure reading resulted in positive reading speed gains. When the exposure to the texts, letter combinations, structures and same lexical items is consistent and more frequent, the probability for automaticity in reading to occur becomes higher. Finally, the participants' reading fluency could also have been positively affected by the increased vocabulary knowledge. This, however, could also be interpreted in a complementary, parallel way: when learners started to read faster, their vocabulary increased.

With respect to the ER impact on the participants' vocabulary knowledge, all the participants in this study scored higher results in their vocabulary knowledge posttests compared to the pre-tests. This is consistent with previous ER research where vocabulary knowledge increased through repeated encountering of individual words (Grabe, 2011; Horst, 2005; Senoo \& Yonemoto, 2014). Participants, in this study, demonstrated a significant improvement in their vocabulary knowledge. They also commented positively that ER aided in their vocabulary increase. Different factors could explain the improvement and positive perceptions after the initial fear of ER.

In the current study, participants were assessed using vocabulary tests in which their items were taken directly from the graded readers rather than the general vocabulary tests typically employed in ER research. This procedural innovation provides a measure of actual word learning directly related to the books read and is a more direct test of the impact of the ER programme. Few studies have focused on assessing the words that students might have encountered while reading extensively 
(e.g., Horst, 2005; Cirocki, 2009). By contrast, the majority of studies that have investigated the effects of ER on vocabulary increase used general vocabulary tests, in which their items might not have been encountered by the student who read extensively (e.g., Yamamoto, 2011).

The final research question investigated the participants' perceptions of the ER impact on their reading fluency and vocabulary knowledge. The participants reported positively on this impact in their diaries as well as their interviews. The most commonly reported reason for viewing ER positively was the provision of varied, easy materials. Providing the participants with a large array of different graded readers with various titles and genres, with the freedom to self-select the materials that interest them could explain the reading fluency and vocabulary growth and their positive perceptions of this impact (Grabe \& Stoller, 2011). In addition, Grabe (2009) noted that the ability to read for a long period of time leads to a sense of achievement and fluency in reading; the participants in this study, and after each one reading at least 15 books, showed positive attitudes towards ER. This could be the result of them enjoying reading and feeling a sense of achievement. Similar perceptions are also found in the literature (e.g., Tabata-Sandom, 2017; Yamashita, 2013). This echoes the findings in Tabata-Sandom's (2017) study which found that L2 Japanese learners held positive perceptions of ER, where they used positive comments such as enjoyable, relaxing and interesting to describe ER. In addition, and similar to the participants in the current study, they mentioned that ER increased their language abilities (e.g., reading fluency, comprehension and vocabulary). It was also noted that the participants showed initial fear of ER at the beginning of the programme as evidenced in their diaries and interviews. However, these feelings started to fade away with time as one participant (S7) commented in their diary: "the more I read, the more I enjoy and break the fear". Support for this argument was supplied in Yamashita (2004), who found that the feelings of enjoyment and comfort correlated with the amount of EFL reading.

Although this study reported positive results of the impact of ER on reading fluency and vocabulary knowledge, there are some limitations to note for future research. This study was done as a piece of action research with a small group of participants and no control group. The investigation focused on the assessment of targeted vocabulary and reading fluency. As no reading comprehension tests were included, it is not possible to determine whether increased reading speed also improved participants' understanding of the text. This remains an open question for future investigations.

\section{Conclusion}

This study has examined the impact of ER on reading fluency and vocabulary knowledge and provided evidence on the effectiveness of ER and that ER yields substantial improvements in reading fluency and vocabulary knowledge in a small group of Jordanian EFL learners. Conducting a classroom-based action research for 
12 weeks, this study sought to avoid some methodological problems found in other ER studies. In addition, this study did not only report positive findings, but also provided details on the amount of reading and how the ER programme was implemented. Additionally, this study showed that the freedom of choice from the wide display of graded readers available to the participants created a positive environment in a context for EFL learners where reading is not a common cultural practice. These findings support the use of easy and comprehensible materials for improving reading fluency and vocabulary knowledge in such learners. A qualitative analysis of participants' perceptions of ER showed that they view the ER practice positively in their language learning, feeling a sense of achievement, which is one of the main drives for reading more and enjoying the process. Such findings could be used to improve the language learning practice in other similar challenging EFL contexts.

\section{Acknowledgements}

I would like to thank the research participants and the administration staff in the language center where the study was conducted for accepting to take part in the study and for their support and collaboration. I am grateful to my colleagues at Birkbeck, University of London, and the reviewers for providing feedback and reviews on previous drafts.

\section{The Research and Publication Ethics Statement}

The Ethics Committee/Board approval for this study was obtained from the University Research Ethics Committee in the Faculty of Arts, Humanities and Social Sciences at Anglia Ruskin University, UK on 08/31/2013. No ethical considerations were violated in this study.

\section{The Conflict of Interest Statement}

In line with the statement of Committee on Publication Ethics (COPE), I hereby declare that I had no conflicting interests regarding any parties of this study.

\section{References}

Alhabahba, M. M., Pandian, A., \& Mahfoodh, O. H. A. (2016). English language education in Jordan: Some recent trends and challenges. Cogent Education, 3(1). https://doaj.org/article/77874dce40a04f018af8fcc75e5a0494.

Al-Homoud, F., \& Schmitt, N. (2009). Extensive reading in a challenging environment: A comparison of extensive and intensive reading approaches in Saudi Arabia. Language Teaching Research, 13(4),383-401.https://doi.org/10.1177/1362168809341508.

Al-Mahrooqi, R., \& Denman, C. (2016). Establishing a reading culture in Arabic and English in Oman. Arab World English Journal, 7(1), 5-17. https://dx.doi.org/10.24093/awej/vol7no1.1.

Al-Mansoor, M., \& Alshoorman, R. (2014). The effect of an extensive reading program on the writing performance of Saudi EFL university students. International Journal of Linguistics, 6(2), 256- 275. https://doi.org/10.5296/ijl.v6i2.5551.

Anderson, N. (1999). Improving reading speed: Activities for the classroom. English Teaching Forum, 37(2), 1-5. 
Bamford, J., \& Day, R. R. (1997). Extensive reading: What is it? Why bother? The Language Teacher, 21, 6-8. Retrieved from https://jalt-publications.org/tlt/articles/2132-extensivereading-what-it-why-bother.

Bamford, J. and Day, R. R. (2004). Extensive reading activities for teaching language. Cambridge: Cambridge University Press.

Beglar, D., \& Hunt, A. (2014). Pleasure reading and reading rate gains. Reading in a Foreign Language, 26(1), 29-48. $\quad$ Retrieved from https://nflrc.hawaii.edu/rfl/April2014/articles/beglar.pdf.

Beglar, D., Hunt, A., \& Kite, Y. (2012). The effect of pleasure reading on Japanese university EFL learners' reading rates. Language Learning, 62, 665-703. https://doi.org/10.1111/j.1467-9922.2011.00651.x.

Bell, T. (2001). Extensive reading: Speed and comprehension. The Reading Matrix, 1, 1-13. Retrieved from http://www.readingmatrix.com/articles/bell/index.html.

Brown, H. D. (2009). Why and how textbooks should encourage extensive reading. ELT Journal, 63(3), 238-245. DOI: 10.1093/elt/ccn041.

Burns, A. (1999). Collaborative action research for English language teachers. Cambridge: Cambridge University Press.

Cirocki, A. (2009). Implementing the ER approach to literature in the EFL secondary classroom: An action research study. In A. Cirocki (Ed.), Extensive reading in English language teaching (pp.521-546). Munich, Germany: Lincom.

Cirocki, A. (2013). The reading portfolio: A tool for learning and assessment in the secondary school EFL classroom. The International Journal of Innovation in English Language Teaching and Research, 2(2), 223-240.

Coghlan, D., \& Brydon-Miller, M. (2014). The Sage encyclopedia of action research. London: Sage.

Creswell, J. W. (2013). Qualitative Inquiry and research design choosing among five approaches (3rd ed.). Thousand Oaks, CA: Sage Publications.

Davis, C. (1995). ER: An expensive extravagance? ELT Journal, 49(4), 329-36. https://doi.org/10.1093/elt/49.4.329.

Day, R.R. (2013). Creating a successful extensive reading program. TESL Reporter, 46(1\&2), $10-20$.

Day, R.R., \& Bamford, J. (1998). Extensive reading in the second language classroom.

Cambridge: Cambridge University Press.

Day, R.R., Bassett, J., Bowler, B., Parminter, S., Bullard, N., Furr, M., Prentice, M., Mahmood, M., Stewart, D., \& Robb, T (Eds.). (2011). Bringing extensive reading into the classroom. Oxford: Oxford University Press.

Dörnyei, Z. (2007). Research methods in applied linguistics: Quantitative, qualitative and mixed methodologies. Oxford: Oxford University Press.

Fernandez de Morgado, N. (2009). Extensive reading: Students' performance and perception. The Reading Matrix, 9, 31-43. Retrieved from http://www.readingmatrix.com/articles/morgado/article.pdf.

Grabe, W. (1988). Reassessing the term "interactive." In P.L.Carrell, J. Devince, \& D.E. Eskey (Eds.), Interactive approaches to second language reading (pp. 56-70). Cambridge: Cambridge University Press.

Grabe, W. (2009). Reading in a second language: moving from theory to practice. New York: Cambridge University Press.

Grabe, W., \& Stoller, F.L. (2011). Teaching and researching reading. (2nd ed.). Harlow, Essex: Pearson. 
Gravetter, F., \& Wallnau, L . (2000) Statistics for the behavioral sciences. Wadsworth / Thomson Learning: Stamford

Gries, S. (2009). Quantitative corpus linguistics with $R$ : A practical introduction. London: Sage.

Hill, D. R., 2008. Graded readers in English. ELT Journal, 62(2), 184-204. https://doi.org/10.1093/elt/ccn006.

Haladyna, T.M. (1999) Developing and validating multiple-choice test items. Lawrence Erlbaum, New Jersey

Horst, M. (2005). Learning L2 vocabulary through extensive reading: A measurement study. The Canadian Modern Language Review, 61, 355-382. DOI: 10.1353/cml.2005.0018.

Horst, M. (2009). Developing definitional vocabulary knowledge and lexical access speed through extensive reading. In Z. Han, \& N. J. Anderson (Eds.), Second language reading research and instruction (pp.40-64). Ann Arbor, MI: The University of Michigan Press.

Huffman, J. (2014). Reading rate gains during a one-semester extensive reading course. Reading in a Foreign Language, 26(2), 17-33. Retrieved from https://nflrc.hawaii.edu/rfl/October2014/articles/huffman.pdf.

Iwahori, Y. (2008). Developing reading fluency: A study of extensive reading in EFL. Reading in a Foreign Language, 20(1), 70-91. Retrieved from https://nflrc.hawaii.edu/rfl/April2008/iwahori/iwahori.html.

Jacobs, G.M., \& Farrell, T.S.C. (2012). Teachers Sourcebook for Extensive Reading. Charlotte, NC: Information Age Publishing.

Koda, K. (2005). Insights into second language reading. New York: Cambridge University Press.

Krahsen, S., 1989. We acquire vocabulary and spelling by reading: Additional evidence for the input hypothesis. The Modern Language Journal, 73, pp.440-464.

Krashen, S. (2011). Free voluntary reading. Portsmouth, NH: Heinemann.

Krashen, S., \& Cho, K.S. (1994). Acquisition of vocabulary from the Sweet Valley Kids series: Adult ESL acquisition. Journal of Reading, 37, 662-667.

Kweon, S.O., \& Kim, H.R. (2008). Beyond raw frequency: Incidental vocabulary acquisition in extensive reading. Reading in a Foreign Language, 20(2), 191-215. Retrieved from https://nflrc.hawaii.edu/rfl/October2008/kweon/kweon.html.

LaBerge, D., \& Samuels, S. J. (1974). Toward a theory of automatic information processing in reading. Cognitive Psychology, 6, 293-323. https://doi.org/:10. 1016/0010-0285(74)90015-2.

Lai, F. K. (1993). The effect of a summer reading course on reading and writing skills. System, 21(1), 87-100.

Mason, B., \& Krashen, S. (1997). Extensive reading in English as a foreign language. System, 25, 81-102. https://doi.org/:10.1016/S0346-251X(96)00063-2.

McLean, S., \& Rouault, G. (2017). The effectiveness and efficiency of extensive reading at developing reading rates. System, 70, 92-106. DOI: 10.1016/j.system.2017.09.003.

McNiff, J. (2014). Writing and doing action research. London: Sage.

Nakanishi, T. (2015). A meta-analysis of extensive reading research. TESOL Quarterly, 49, 637. https://doi.org/10.1002/tesq.157.

Nathan, R. G., \& Stanovich, K. E. (1991). The causes and consequences of differences in reading fluency. Theory into Practice, 30, 176-184. https://doi.org/:10. 1080/00405849109543498.

Nishino, T. (2007). Beginning to read extensively: A case study with Mako and Fumi. Reading in a Foreign Language, 19(2), 76-105. Retrieved from https://nflrc.hawaii.edu/rfl/October2007/nishino/nishino.html. 
Perfetti, C.A. (2007). Reading ability: Lexical quality to comprehension. Scientific Studies of Reading, 8, 293-304. https://doi.org/10.1080/10888430701530730.

Rajab, H., \& Al-Sadi, A. (2015). An empirical study of reading habits and interests of Saudi university EFL learners. International Journal of Linguistics, 7(2), pp.117. https://doi.org/10.5296/ijl.v7i2.7034.

Revesz, A. (2012). Coding second language data validly and reliably. In A. Mackey, \& S. M. Gass (Eds.), Research methods in second language acquisition: A practical guide (pp. 203221). Oxford: Wiley-Blackwell.

Ro, E., \& Chen, C. (2014). Pleasure reading behavior and attitude of non-academic ESL students: A replication study. Reading in a Foreign Language, 26(1), 49-72. Retrieved from https://nflrc.hawaii.edu/rfl/April2014/articles/ro.pdf.

Robb, T., \& Susser, B. (1989). Extensive reading vs. Skills building in an EFL context. Reading in a Foreign Language, 5, 239-251.

Schumann, F., \& Schumann, J. (1997). Diary of a language learner: An introspective study of second language learning. In H.D. Brown, C. Yorio, \& R. Crymes (Eds.), Teaching and learning English as a second language: Trends in research and practice (pp.241-249). Washington, DC: TESOL.

Senoo, Y., \& Yonemoto, K. (2014). Vocabulary learning through extensive reading: A case study. The Canadian Journal of Applied Linguistics, 17(2), 1-22. https://doaj.org/article/d502969336af4b4283e109235b9c6c46.

Smith, F. (1994). Understanding reading: A psycholinguistic analysis of reading and learning to read. (5 $5^{\text {th }}$ ed.). Hillsdale, NJ: Erlbaum.

Tabata-Sandom, M. (2017). L2 Japanese learners' responses to translation, speed reading, and" pleasure reading" as a form of extensive reading. Reading in a Foreign Language, 29(1), 113-132.

Yamamoto, Y. (2011). Bringing the gap between receptive and productive vocabulary size through extensive reading. The Reading Matrix, 11(3), 226-242. Retrieved from http://www.readingmatrix.com/articles/september_2011/yamamoto.pdf.

Yamashita, J. (2004). Reading attitudes in L1 and L2, and their influence on L2 extensive reading. Reading in a Foreign Language, 16, 1-19.

Yamashita, J. (2013). Effects of extensive reading on reading attitudes in a foreign language. Reading in a Foreign Language, 25, pp.248-263.

\section{Copyrights}

Copyright for this article is retained by the author(s), with first publication rights granted to the Journal.

This is an open-access article distributed under the terms and conditions of the Creative Commons Attribution license (CC BY-NC-ND) (http://creativecommons.org/licenses/by-nc-nd/4.0/). 